\title{
A potential intraoperative disaster averted: Preduodenal portal vein compressing a preduodenal common bile duct
}

\author{
Ameet Kumar and Mahima Pandey
}

Department of Surgery, 5 Air Force Hospital, Jorhat, Assam, India

\begin{abstract}
Familiarity with the anatomy is paramount for conduct of safe surgery for a surgeon. Anomalies with the biliary and hepatic arterial system are common but portal vein anomalies are least common. A preduodenal portal vein has been reported in about 100 cases but a combination of preduodenal portal vein with preduodenal common bile duct is extremely rare with only 9 cases being reported. We report a one such case and discuss the embryological basis for the peculiar anatomy observed in our case which has never been reported earlier. We also reviewed the reported cases in literature. (Ann Hepatobiliary Pancreat Surg 2021;25:145-149)
\end{abstract}

Key Words: Preduodenal portal vein; Preduodenal common bile duct; Jaundice; Choledocholithiasis; Choledochojejunostomy

\section{INTRODUCTION}

Familiarity with the anatomy is paramount for conduct of safe surgery for a surgeon. The availability of crosssectional imaging has widely helped surgeons review the anatomy and avoid an intra-operative surprise or disaster. They say that there is nothing called as a normal anatomy when it comes to the hepato-biliary region with reported anomalies exceeding 40\%. ${ }^{1}$ While anomalies with the biliary and arterial system are common, portal vein (PV) anomalies are least common. ${ }^{2}$ A preduodenal PV (PDPV) has been reported in about 100 cases but a combination of PDPV with preduodenal common bile duct (PDCBD) is extremely rare with only 9 cases being reported. ${ }^{3,4}$ Further, the embryological basis for the peculiar anatomy observed in our cases has never been reported earlier. We report this case that presented with jaundice and briefly review the relevant embryology and the reported cases in literature.

\section{CASE}

A 50-year-old lady presented with jaundice and pain in right hypochondrium of 2 months' duration. She was ic- teric and on abdominal examination the gall bladder was not palpable. No other abnormality was noticed. Laboratory investigations revealed normal hemogram and deranged liver functions (total bilirubin $12 \mathrm{mg} / \mathrm{dl}$; direct $9.7 \mathrm{~g} / \mathrm{dl}$, alkaline phosphatase $452 \mathrm{U} / \mathrm{L}$ and normal transaminases). An ultrasound of abdomen reported dilated intrahepatic and common bile duct (CBD) with a cut off at its distal end. A contrast-enhanced computed tomography (CECT) of the abdomen with a magnetic resonance cholangiopancreatography (MRCP) was reported as cholelithiasis with choledocholithiasis. A laparoscopic cholecystectomy with CBD exploration (CBDE) was planned. During the surgery, there were dense adhesions around the gallbladder/CBD and after some meticulous dissection, the CBD was identified. However, there were two tubular structures and the anatomy was unclear. So a decision was taken to convert to an open surgery. On laparotomy, we noticed that the two tubular structures were actually a PDPV and PDCBD (Fig. 1). What was more interesting was that the PDPV was on the right lateral aspect of the PDCBD, crossing it in it lower part, possibly causing its compression and leading to development of choledocholithiasis. A cholecystectomy, CBDE with stone clearance was done and a roux-

Received: August 1, 2020; Revised: September 8, 2020; Accepted: September 8, 2020

Corresponding author: Ameet Kumar

Department of Surgery, 5 Air Force Hospital, Jorhat 785005, Assam, India

Tel: +916002092231, E-mail: docam@rediffmail.com

Copyright (C) 2021 by The Korean Association of Hepato-Biliary-Pancreatic Surgery

This is an Open Access article distributed under the terms of the Creative Commons Attribution Non-Commercial License (http://creativecommons.org/ licenses/by-nc/4.0) which permits unrestricted non-commercial use, distribution, and reproduction in any medium, provided the original work is properly cited. Annals of Hepato-Biliary-Pancreatic Surgery • pISSN: 2508-5778 - eISSN: 2508-5859 


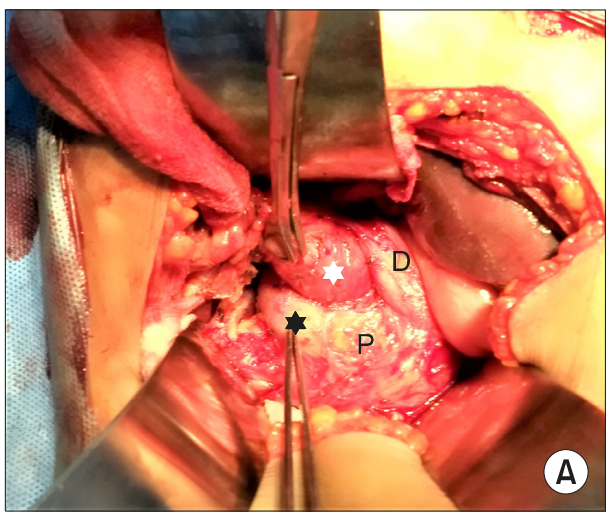

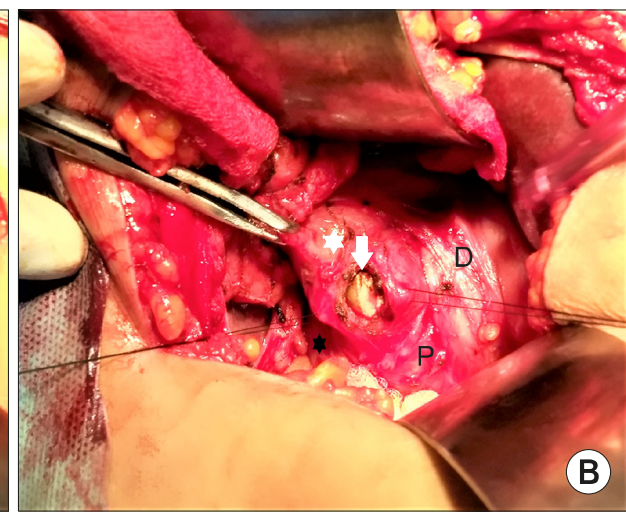

Fig. 1. Intraoperative picture showing preduodenal portal vein $(\mathrm{PD}$ PV) and preduodenal CBD. PD PV (black star) to the right of PDCBD (white star). The duodenum (D) is coursing behind and pancreas $(\mathrm{P})$ is in front of these structures.
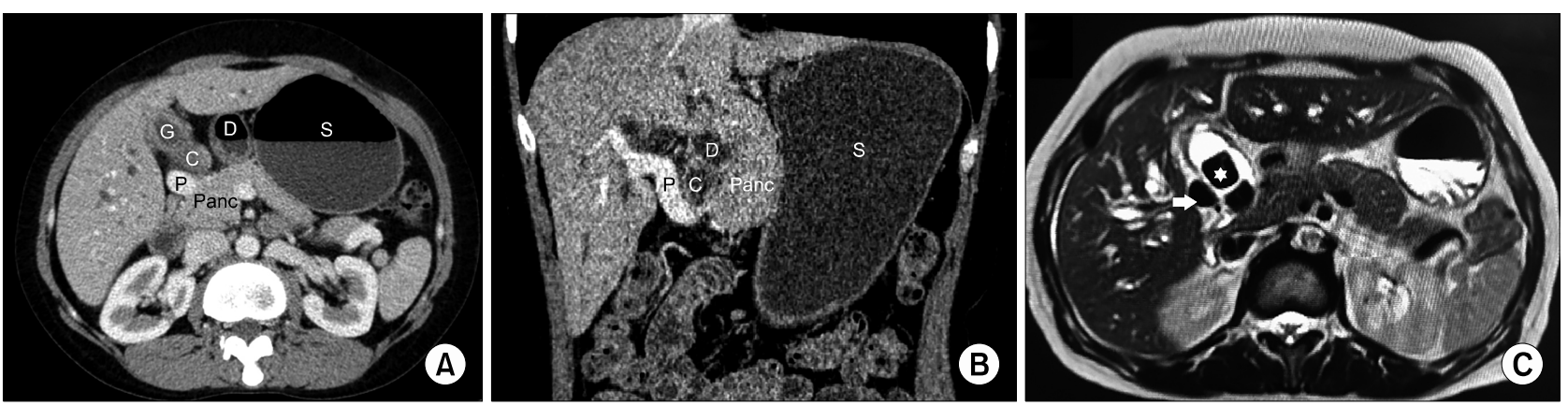

Fig. 2. Pre-operative imaging of the patient. (A) Axial CT scan image showing portal vein $(\mathrm{P})$ and $\mathrm{CBD}(\mathrm{C})$ in front of duodenum (D) and pancreas (Panc). (B) Coronal reformatted CT scan image showing portal vein (P) crossing the CBD (C) and causing compression. Both these structures are in front of duodenum (D) and pancreas (Panc). (C) MRI T2 weighted axial image showing choledocholithiasis (white star) and portal vein (white arrow) to right of CBD. S, stomach; G, Gallbladder.

en-y choledochojejunostomy was added keeping the obstruction by PDPV in mind. Post surgery, we reviewed the imaging and it corroborated our intra-operative findings (Fig. 2).

\section{DISCUSSION}

A PDPV was first described by Knight ${ }^{5}$ in 1921 and the first surgery in a case of PDPV was done by Schnitzler ${ }^{6}$ in 1926 for duodenal obstruction. A PDPV can be associated with various anomalies but an associated PDCBD is the least common. First described by Stengel ${ }^{7}$ in 1934 , only 9 cases have been reported so far., ${ }^{3,4}$

Embryologically, the PV is formed by paired vitelline veins having three communications; the cranial intra-hepatic, the middle retroduodenal and the caudal preduodenal. The cranial and caudal communications along with the proximal right and distal left vitelline veins disappear to form the ' $\mathrm{S}$ ' shaped retroduodenal $\mathrm{PV}{ }^{8}$. Development of the pancreas and the biliary system occurs simultaneously with the formation of the PV, as the ventral pancreatic bud rotates clockwise (seen from cephalic end) around the duodenum to meet the dorsal bud and fuses with it. This rotation places the PV and CBD posterior to both the pancreas and the duodenum (Fig. 3B).

An isolated PDPV occurs when the middle communication disappears and the caudal communication persists (Fig. 3A). The embryology behind a PDCBD is unclear. It could arise due to counter-clockwise rotation of the duodenum. ${ }^{9}$ In our case it seems the cause of both PDPV and PDCBD is likely to be due to a common occurrence - the counterclockwise rotation (Fig. 3C). This hypothesis probably explains the finding of the PDPV on the right lateral aspect of the PDCBD and the absence of intestinal malrotation. To the best of our knowledge, this unique anatomy and the embryological basis has never been reported in literature. In cases reported in literature, where specified, the PDPV was found to the left of PDCBD which can arise due to primary abnormal formation of $\mathrm{PV}$ and reverse rotation of duodenum or due to situs inversus and reversed 

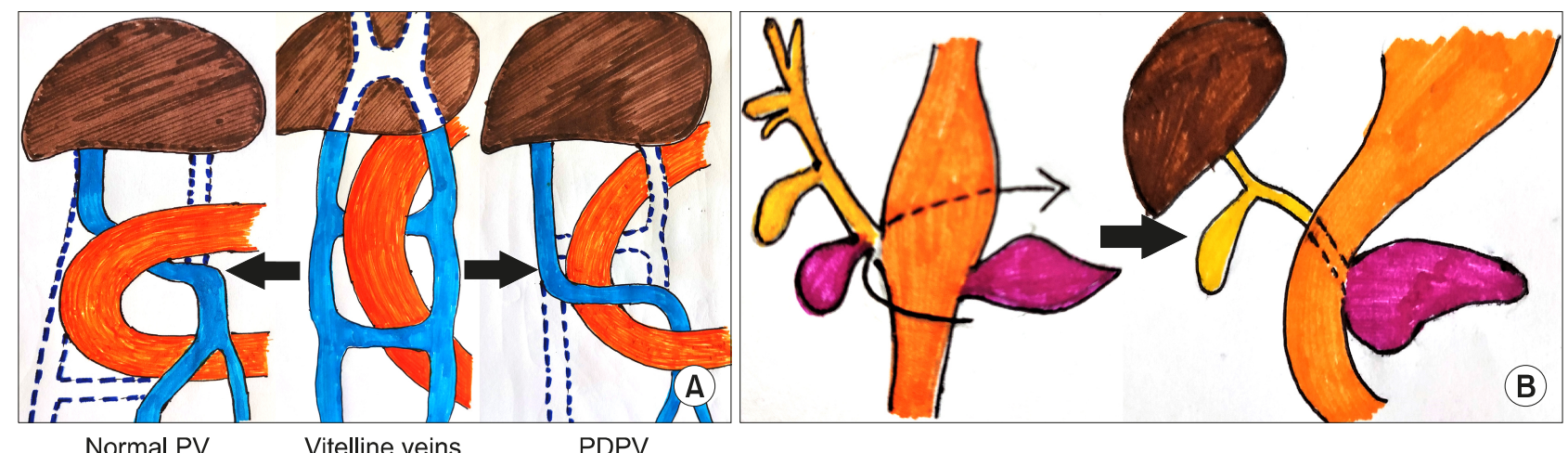

Normal PV

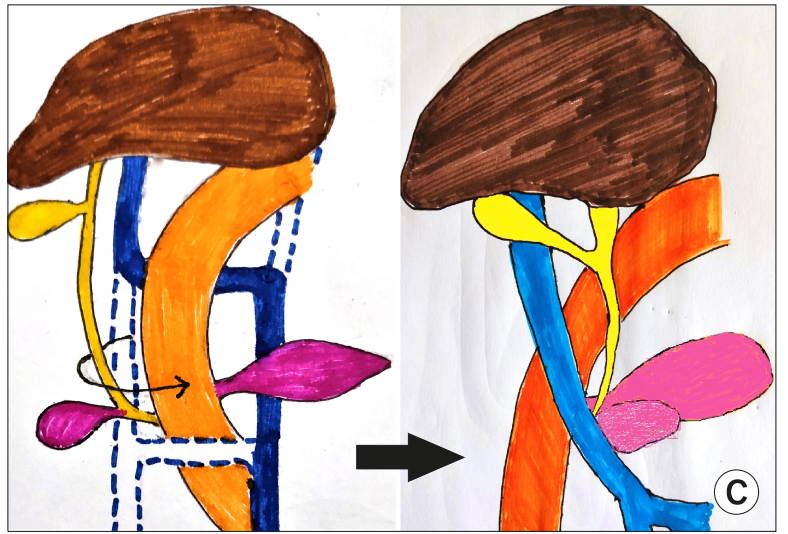

Fig. 3. Illustration showing the embryological development. (A) Development of a normal (PV) and preduodenal portal vein (PDPV) from the paired vitelline veins. (B) Development of CBD and pancreas with normal counterclockwise rotation of the duodenum. (C) Reverse rotation during development leading to a preduodenal portal vein and CBD in our case (blue-portal vein; yellow-CBD; pink-pancreas; brown-liver, and orange-stomach/duodenum).

Table 1. Summary of all cases of preduodenal portal vein associated with preduodenal CBD reported in literature

\begin{tabular}{|c|c|c|c|c|c|c|}
\hline $\mathrm{S} 1$ & Year & Author & Age/sex & Diagnosis & Other associated anomalies & Treatment \\
\hline 1 & 1934 & Stengel $^{7}$ & $9 \mathrm{~m} / \mathrm{F}$ & At autopsy & $\begin{array}{l}\text { Malrotation, ventro-dorsal pancreas, } \\
\text { abnormal ramification of celiac axis } \\
\text { and superior mesenteric artery }\end{array}$ & - \\
\hline 2 & 1962 & $\begin{array}{l}\text { Debray } \\
\text { et al. }\end{array}$ & $65 \mathrm{y} / \mathrm{M}$ & At autopsy & $\begin{array}{l}\text { Malrotation, ventral pancreas, } \\
\text { partial annular pancreas, no tail of } \\
\text { pancreas, inversion of major vessels }\end{array}$ & - \\
\hline 3 & 1971 & $\begin{array}{l}\text { Braun and } \\
\text { Cuendet }^{11}\end{array}$ & $8 \mathrm{~d} / \mathrm{M}$ & Duodenal atresia & $\begin{array}{l}\text { Malrotation, duodenal atresia, } \\
\text { common mesentery }\end{array}$ & Duodenojejunostomy \\
\hline 4 & 1971 & $\begin{array}{l}\text { Braun and } \\
\text { Cuendet }^{11}\end{array}$ & $4 \mathrm{~d} / \mathrm{M}$ & Duodenal web & Duodenal web, mobile right colon & $\begin{array}{l}\text { Excision of web, } \\
\text { duodenoplasty }\end{array}$ \\
\hline 5 & 1976 & $\begin{array}{l}\text { Uchiyama } \\
\text { et } \text { al. }^{12}\end{array}$ & $3 \mathrm{~m} / \mathrm{M}$ & Biliary atresia & Malrotation, congenital biliary atresia & $\mathrm{R}-\mathrm{Y}$ portoenterostomy \\
\hline 6 & 1985 & Patti et al. ${ }^{13}$ & $1 \mathrm{~d} / \mathrm{F}$ & $\begin{array}{l}\text { Esophageal and } \\
\text { duodenal atresia }\end{array}$ & Esophageal and duodenal atresia & Duodenojejunostomy \\
\hline 7 & 1996 & Leung et al. ${ }^{9}$ & $32 \mathrm{y} / \mathrm{F}$ & Choledocholithiasis & Short small bowel mesentery & Choledochoduodenostomy \\
\hline 8 & 2004 & Yi et al. $^{3}$ & $75 \mathrm{y} / \mathrm{M}$ & At autopsy & $\begin{array}{l}\text { Situs inversus totalis, malrotation, } \\
\text { short pancreas, bilobed/accessory } \\
\text { spleen, and abnormal ramification of } \\
\text { the celiac axis, superior mesenteric } \\
\text { artery and renal arteries }\end{array}$ & - \\
\hline 9 & 2009 & Shah et al. ${ }^{4}$ & $75 \mathrm{y} / \mathrm{F}$ & Hepatolithiasis & Polysplenia, missing tail of pancreas & Left lateral Sectionectomy \\
\hline 10 & 2020 & $\begin{array}{l}\text { Present } \\
\text { case }\end{array}$ & $50 / \mathrm{F}$ & Choledocholithiasis & None & Choledochojejunostomy \\
\hline
\end{tabular}

A part of the data is derived from reference no. 9 
rotation of duodenum.

A summary of cases reported in literature is placed at Table 1..$^{3,4,7-13}$ Ours is only the $10^{\text {th }}$ case, albeit with a unique altered anatomy and the embryological basis for the same. The age at diagnosis is equally split between adults and children/neonates with a slight female preponderance. Most cases have been associated with some degree of intestinal malrotation. In addition to these cases there has been one case reported of an isolated PDCBD without a PDPV. ${ }^{14}$ This was a neonate who was operated for duodenal atresia and while performing a duodenoduodenostomy, the PDCBD was accidentally transected which was repaired over a stent.

What could be the clinical significance of this anomaly? Three cases have been diagnosed at autopsy meaning that such cases could remain asymptomatic throughout their life. The significance of this anomaly would be on two accounts. First, the anomalous relationship could lead to difficulties in hepato-biliary-pancreatic surgery where a failure to recognize the altered arrangement of the portal vein and CBD early in dissection could lead to accidents and disastrous consequences like injury to the PV. Second, the abnormal arrangement may cause obstruction to the CBD leading to choledocholithiasis, as in our case, and/or hepatolithiasis. $^{4,9}$

The hepatobilary region will continue to surprise surgeons with its anatomical variations. It is important to study the imaging meticulously to pick up anomalies, if any, to prevent intraoperative surprises or disasters especially in laparoscopic surgery because of the absence of tactile feedback and the total reliance on visual cues. In our case, the radiologists could not pick up the anomaly because of being unaware of this entity that is so rare. We too were wiser only after discovering the anomaly on conversion and when we looked up literature. This particular case had dense adhesions which took us about an hour to identify what we thought was the CBD and were lucky that we did not enter into the PV thinking it is the CBD. Though rare, surgeons must be aware of a PDPV and if associated with jaundice/choledocholithiasis, there probably is an associated PDCBD too.

\section{CONFLICT OF INTEREST}

The authors have no potential conflicts of interest to disclose.

\section{INFORMED CONSENT}

The patient provided informed consent for the publication of this report and any accompanying images.

\section{ORCID}

Ameet Kumar: https://orcid.org/0000-0002-0762-150X

Mahima Pandey: https://orcid.org/0000-0001-8148-6775

\section{AUTHOR CONTRIBUTIONS}

Conceptualization: AK. Data curation: AK. Writing original draft: AK, MP. Writing - review \& editing: AK, MP.

\section{REFERENCES}

1. Catalano OA, Singh AH, Uppot RN, Hahn PF, Ferrone CR, Sahani DV. Vascular and biliary variants in the liver: implications for liver surgery. Radiographics 2008;28:359-378.

2. Goussous N, Cunningham SC. Prepancreatic postduodenal portal vein: a case report and review of the literature. J Med Case Rep 2017;11:2.

3. Yi SQ, Tanaka S, Tanaka A, Shimokawa T, Ru F, Nakatani T. An extremely rare inversion of the preduodenal portal vein and common bile duct associated with multiple malformations. Report of an adult cadaver case with a brief review of the literature. Anat Embryol (Berl) 2004;208:87-96.

4. Shah OJ, Robbani I, Khuroo MS. Preduodenal portal vein with preduodenal common bile duct: an extremely rare anomaly. Am J Surg 2009;197:e43-e45.

5. Knight HO. An anomalous portal vein with its surgical dangers. Ann Surg 1921;74:697-699.

6. Schnitzler J. [About a peculiar malformation with stenosis of the gastric outlet]. 1926;22:723-726. German.

7. Stengel F. [About two cases of preduodenal course of the portal vein with the normal position of the stomach and duodenum]. Z Anat Entwicklungsgesch 1934;102:661-689. German.

8. Marks C. Developmental basis of the portal venous system. Am J Surg 1969;117:671-681.

9. Leung LC, Wong CY, Wong CM, Cheung KK. Choledocholithiasis in anomalous biliary system. Aust N Z J Surg 1996;66:416417.

10. Debray C, Delmas A, Hakim M, Mugnier B. [Preduodenal portal vein and common bile duct. Surgical significance]. Presse Med 1962;70:1675-1676. French.

11. Braun P, Cuendet A. Preduodenal portal vein. Prog Pediatr Surg 1971;3:121-140.

12. Uchiyama T, Niichu K, Hamada Y, Kimura H. Produodenal portal vein with congenital biliary atresia and intestinal malroration. Jpn J Pediat Surg Med 1976;8:629-634.

13. Patti G, Marrocco G, Mazzoni G, Catarci A. Esophageal and duodenal atresia with preduodenal common bile duct 
and portal vein in a newborn. J Pediatr Surg 1985;20:167168

14. Muraoka I, Ohno Y, Kobayashi K, Honda R, Kubo T, Kanematsu
T. Preduodenal position of the common bile duct associated with annular pancreas: case report and literature review. Pancreas 2005; $31: 283-285$ 